\title{
A CASE OF DECIDUOMA MALIGNUM.
}

\author{
By J. K. KELLy, M.D., Physician for Diseases of Women, Glasgow Royal \\ Infirmary; Lecturer on Gyncecology, St. Mungo's College; and JoHN \\ H. Teacher, M.A., M.B. C.M., Underkepeer in the Pathological \\ Department of the Hunterian Museum, Glasgow University.
}

\section{(Plates XXXVI.-XXXIX.)}

Tre name Deciduoma Malignum has been used to designate the case which is described in the following pages, because it is the name under which Sänger first called attention to a malignant tumour of the uterus, developing in connection with child-birth or abortion, and because it is the name which has received most general acceptance as a designation for cases of this nature. As will appear from the following description the name is not a good one for the particular tumour under consideration, which appears to have originated not from decidua, but from the epithelial cells covering the villi of the chorion.

Abstract of Clinical History, by Dr. Kelly, who had charge of THE Patient WHILE IN HIS WARD IN THE RoYal INfiRmary.

2nd February 1897.-Mrs. L., æet. 27, 2-para, now in her third pregnancy, consulted her medical attendant for slight hæmoptysis. This was supposed to be due to incipient phthisis, as the expiratory murmur at the right apex was prolonged. This slight hæmoptysis continued, and on 20th April there was some vaginal discharge.

18th June.-Labour came on, and a mole about the size of a Jaffa orange was expelled. No tumour was then detected in the vagina. Vaginal hæmorrhage continued, and on 7th August a small tumour in the vagina was detected. It was like a foreign body, about the size of a shilling, lying on the anterior vaginal wall. An attempt to separate it from the vaginal wall caused such severe hæmorrhage that the vagina required plugging.

10th August.-- "An ulcerating hæmatoma," which was not examined, was excised from the anterior vaginal wall. Bleeding having persisted, patient was received into hospital on the 20 th of September. There was then an elongated finger-like mass on the anterior vaginal wall, and a rounded nodule on the posterior wall, and the nterus itself was enlarged. Details of the case after admission to hospital are given in the Glasgow Medical Journal, January 1898, under "Remarks preceding a Demonstration in the Glasgow Royal Infirmary." 
The chief points to be noted are: On the 24th September a severe uterine hæmorrhage with collapse; on 28th September a slight cough and an appearance of streaks of blood in the expectoration. On 3rd October a recurrence of the uterine hæmorrhage, and thereafter a rapid increase in the size of the uterus and decline of strength, with death on the 19th October, four months after the abortion.

\section{Report of the Sectio, by Dr. Charles Workman, Pathologist to THE ROYaL InfIRMary.}

External Appearances.-A well-developed and well-nourished body, with great blanching of the skin; pupils equal and medium. Post-mortem rigidity is pronounced.

Thorax.-On opening the thorax, the pericardium is found to contain about 2 oz. of clear serum. The lungs are free from adhesions, and are the seat of evident secondary malignant growths. The surface is of a peculiar mottled appearance, some parts being exsanguineous, while others are deeply congested, this giving rise to distinct demarcation of the lobules of the lungs. Otherwise these organs present healthy characters.

Heart.-Aortic and pulmonary curtains are competent, and these and the other valvular structures present healthy characters ; mitral orifice has a circumference of $115 \mathrm{~mm}$.; tricuspid, $135 \mathrm{~mm}$. The muscular tissue of the heart wall is very pale and mottled, indicating fatty degeneration; the coronary arteries are quite healthy; the aorta is very slightly atheromatous.

Abdomen.-On opening the abdomen the organs are seen to be very pale, and the uterus shows prominent above the pelvic brim, its posterior wall being the seat of a large and very vascular tumour. The liver is pale and soft; on section it shows evidence of fatty change and passive hyperæmia; no signs of any secondary tumours can be found in it.

The spleen is large and very pale; on section it has a mottled appearance, the various areas having a very different density; the condition is probably due to secondary tumour formation (subsequent microscopic investigation disproved this). The kidneys are pale, but otherwise present very healthy characters; no signs of tumour formation are found. Stomach appears healthy.

Pelvis.-The pelvic organs were removed en masse. The rectum presents quite healthy characters, though the lymphatic glands in its neighbourhood are involved by the secondary growths; the vagina is the seat of several round tumour masses projecting into its lumen. The posterior wall of the uterus is the seat of a tumour, the size of a large orange, and having to the naked eye quite the appearance of placental tissue; in the right Fallopian tube there is a small rounded nodule of similar character. The ovaries are normal. The bladder appears healthy.

\section{Report of the Dissection of the Specimen, and the Microscopic Appearances, by Dr. Teacher.}

The specimen, as received for dissection and microscopic examination, consisted of the entire contents of the pelvis as removed at the autopsy, cut off at the level of the internal sphincter ani and hymen, so as to leave the external parts intact. Plate XXXII. Figs. 1 and 2 are from photographs of the front and back of it after dissection. The uterus, considerably enlarged by the tumour of its posterior wall, and apparently raised somewhat above the position of the impregnated 
viscus relative to the bladder and rectum, occupies the middle. The bladder had been laid open in front and stuffed with cotton wool; it is displaced somewhat to the left. The urethra is also slit open in front. The rectum ran up the back of the mass, passing obliquely to the left.

Dense swellings were felt on either side of the vagina and cervix uteri, which turned out to be secondary tumours; they are shown to be of this nature by a projecting mass on the left side, which was incised at the post-mortem examination. This nodule was enclosed in a thin fibrous capsule; it has spread out on being incised, as if it had been under considerable tension. It shows the characteristic appearance of the tumour-a brown mass of blood clot intersected by irregular strands of paler tissue, which are the proper tumour tissue.

The bladder, rectum, vagina, and secondary tumour masses were covered with the usual adipose and areolar tissue, which was carefully removed, and the appearances revealed, noted down as observed. The cut ends of the internal iliac vessels were found about the base of the broad ligaments opposite the cervix, and, as the dissection proceeded, their branches were followed up to the uterus, bladder, and vagina. The dissection was directed to clearing the tumour masses at the sides of the vagina and cervix, and showing their relations to these organs, and to the bladder and rectum. The various blood vessels met in this process were preserved or cut away after being identified, as seemed most expedient. The rectum and its vessels being found quite uninvolved were cut away entirely, to expose the back of the vagina. The anterior parts of the bladder were also removed. There is no tumour in the bladder itself; the condition of its vessels will appear later.

The tumour masses on either side of the vagina and cervix are so similar to one another that one description suffices for both. Each may be considered as having two parts. The upper part lying opposite the cervix and top of the vagina occupies the position to which converge the blood vessels, lymphatics, and nerves of the uterus, vagina, and greater part of the bladder. The lower part, continuous with this, has the appearance of a huge mass of varicose veins attached to the vagina, and extending about halfway to the ostium vaginæ. It is in fact a mass of vaginal veins distended with tumour and blood clot.

The upper part is a more complex structure. It consists of a mass of brown tumour about the size of a walnut, on the right; on the left, slightly smaller. The ends of numerous blood vessels project from it, and others run over its surface, mostly involved by extension of the growth through their walls. The mass is quite detached from the side of the cervix, separated from it by a thin layer of normal tissues, through which the ureters are traced, quite unaffected on both 
sides. These are marked with bristles, which were easily passed through them.

The tumour is partly ill-defined from the surrounding adipose and areolar tissues, partly enclosed in a thin fibrous capsule. The surface of the former part was more or less cut away in the dissection; the shavings, examined microscopically, showed areolar and adipose tissues, and small blood vessels infiltrated with tumour cells.

The capsules were, in some parts, remains of blood vessel walls, in others the remains of the capsules of lymphatic glands. A portion of uninfected lymphatic gland, with tumour tissue in adjacent vessels, and a small portion of adenoid tissue, infiltrated and almost destroyed by tumour cells, were recognised by the microscope. There was less difficulty about the recognition of the blood vessels. Numbers of these are seen rising from bladder, vagina, or uterus, and running up to the tumour mass apparently normal, and there becoming distended with what looks like a mass of thrombus, but is really a secondary tumour growing within then. A large vein (seen best from behind) on the left side, coming from the bladder, filled with a long oval mass of tumour, lay loosely attached to the main tumour; on detaching it, the wall next the tumour was found to be quite recognisable as venous wall, but so altered in its texture by the invading tumour as to break down on the slightest touch. That this was really due to infiltration by the tumour processes, was proved by microscopic examination of a wedge cut out of a similar invaded vein at the other side (Plate XXXVI. Fig. 1 and Plate XXXVII. Fig. 5).

The uterine artery and veins were traced from the cut ends outside the tumour mass up to the side of the uterus. The main trunk of the artery on the right side runs in a groove on the top of the tumour. Its external coat appears to be infiltrated, but its middle coat is quite intact; right up to the side of the uterus it is wholly free from tumour invasion (Plate XXXVI. Fig. 2). The vesical arteries (cut away) were in a similar condition on this side; on the other, the arteries pass clear above the tumour. The veins were less easily traced, as most of them are involved in the tumour. Above it they again emerge clear, and pass up to the side of the uterus in that condition; there, some of them, which pass into the primary tumour, are found distended with tumour tissue. It is evident from these facts, that the secondary tumours at the sides of the cervix have arisen from tumour tissue, carried, not by the veins, but by the lymphatics, which has been arrested by the glands on the internal iliac artery, and has grown in them and spread from them into the veins. The involvement of the veins and spread of the tumour in them, will be referred to after the microscopic characters of the tumour have been described; the metastases in the lungs are, of course, due to the extension by the veins.

The posterior wall of the vagina was removed to show the 
condition of the interior. It is found that there was no ulceration into it. Two nodules in its wall were cut in the removal; they appear like round masses of blood clot; they are covered by a distinct layer of mucous membrane of considerable thickness. One of them bulged into the rectum, bnt there was no sign of infiltration in the rectal wall. Some of the tumour nodules bulge the peritoneum, but there is no ulceration into its cavity. The ovarian vessels and the anastomosing branches from the uterine vessels to them are free from tumour growth, except, perhaps, one of the latter on the right, which runs in a part of uterine wall where the tumour has approached very near to the surface, and appears to have extended into it. The ovarian and uterine vessels are enlarged as in pregnancy. The lumbar lymphatic glands had not been preserved for examination. Neither were the bronchial glands.

\section{Microscopic Examination.}

Methods used.-The tissues were fixed in alcohol, and were in general fairly well preserved, except as regards karyokinetic figures, which were not satisfactory. The sections were all prepared by the paraffin process, and fixed on albuminised slides. The stain generally used was hæmalum and eosin; Weigert's fibrin stain, Van Giessen (picric acid and acid fuchsine for connective tissues), and picro-carmine were also used for special purposes.

Description of microscopic structure.-To the naked eye the uterine tumour appears like a great mass of blood clot of a brown colour, permeated by strands of lighter coloured tissue (which is the tumour tissue proper), growing from the whole extent of the posterior wall, enlarging the uterus, filling its cavity, and also extending outwards through its muscular wall almost to the peritoneum (Plate XXXVI. Fig. 1 and Plate XXXVII. Fig. 3). The exterior of the tumour is indistinctly lobulated, of a mottled brown and white colour, white where there is much uterine wall, brown where only a thin stratum of it covers the new growth.

Microscopically, the tumour consists of processes of cells and blood. Sections were prepared from a wedge which included almost the whole thickness of the tumour, and the remains of the uterine wall. The central, the oldest parts of the tumour, are in a state of complete necrosis. The necrosed zone, in fact, makes up the greater part alike of the primary and of the larger secondary growths, but even where necrosis is complete, the tumour tissue is usually to be distinguished from the blood clot by some remains of the cells, rounded and swollen, and without nuclear staining, but still recognisable. Proceeding outwards from the necrosed area, the tumour cells are met with in all stages of degeneration, and the amount of blood clot between the masses of them becomes less, till the zone which may be 
called the growing zone is reached. The inner part of this consists of young cell masses with comparatively little blood among them, and remains of the structures composing the organ in which the growth is situated. Its outer part consists of processes of cells, like the epithelial processes of a carcinoma, infiltrating the surrounding tissues (Plate XXXVII. Figs. 4 and 6). These different parts-(1) the area of complete necrosis, (2) the zone showing cell masses in different stages of degeneration, and (3) the growing zones-are seen in all the tumours, except the very youngest of the metastases and some of the old ones (such as that in the Fallopian tube and the lower one seen in section in the vagina), where the whole thing is a rounded mass of necrosed tissue and blood clot, the latter predominating. The breadth of the zone of growing or only slightly degenerated tumour cells varies greatly in different tumours and different parts of the same tumour; sometimes there are hardly any cells at the edge of the mass of blood clot, at others there is a broad belt of cells. The characters of the growth in the primary and in the secondary tumours are identical.

The character and nature of the cell masses are best seen in the growing zone, especially in certain places, in the primary and secondary tumours where they seem to have grown freely in fresh uncoagulated blood and in the lymph spaces around blood vessels (Plate XXXVII. Fig. 7 and Plate XXXVIII. Figs. 8 to 10). Where they are infiltrating the old tissues, their characters cannot be made out so distinctly. Degenerative changes produce a variety of appearances which will be referred to later on.

Two kinds of cell formation are distinctly recognisable. In the freely expanding parts of the tumour the element which bulks largest consists of masses of cells with fairly distinct outlines, clear protoplasm, and oval or round nuclei of considerable size, which stain rather lightly with hæmalum, carmine, or other nuclear stains, and show a very distinct intranuclear network. Many of these cells, even in the young masses, show vacuolation and retraction of the protoplasm from the nucleus, so as to give the appearance of a network of threads of protoplasm enclosing round or polygonal spaces, in which lie the nuclei (Plate XXXIX. Fig. 13). The nuclei in these parts become large and distorted, and in the more advanced stage of degeneration lose their staining properties. Forming an outer edge to these cell masses there is usually recognisable a ring of smaller and more deeply stained nuclei, some round but most oval, and many a very long oval or spindle shape, varying considerably in size, and surrounded by a small amount of protoplasm, which appears less clear than that of the preceding set of cells, from being finely granular and staining deeply with eosin, while the other remains almost uncoloured. The protoplasm of this ring is not differentiated into separate cells. It is continuous with the first mentioned set of cells, demarcated from them only by 
a slight boundary like that between the individual cells of the first class, and by the change in the appearance of its protoplasm. Its free surface appears to be naked to the surrounding blood. Here and there processes of this layer, with nuclei in them, extend some little distance into the masses of cells of the first class. These two kinds of cells may be called the inner and the outer layer of the cell masses (Plate XXXVII. Fig. 7 and Plate XXXVIII. Figs. 8 to 10 ).

The infiltrating processes of tumour show both kinds of cells. They are narrow processes of nuclei and protoplasm, undifferentiated into distinct cells, which appear to have insinuated themselves into the interstices of the surrounding old tissues (whatever they may be, uterine muscle, wall of blood vessel, areolar, adipose, or lung tissue) (Plate XXXVII. Figs. 3 to 6 ). In the most outlying and narrowest processes the deeply stained elongated nuclei of the outer layer are most prominent, but wherever a mass of cells of any size appears, it is composed mostly of the cells of the inner set. Both classes of nuclei are distinguished from those of connective, granulation, muscular, or adenoid tissues by being very much larger. They are also rather larger than the nuclei of vaginal epithelium or of that of bronchial glands.

There is a third cellular element, apparently derived from the outer layer of the cell masses, which forms a very striking feature of the tumour. This is the presence of large plasmodial masses of finely granular undifferentiated protoplasm, staining deeply with eosin, in which lie numbers of nuclei of very various shapes and sizes. Vacuoles, a few of which contain blood, are also frequently seen in the protoplasm. These plasmodia are continuous with the outer layer of the cell masses, and bear the same relations to the cells of the inner division. They are often of large size, and contain many nuclei which are not set at any regular distance from one another, rather tending to be gathered together into clumps.

The nuclei vary enormously in size, varying from that of those of the outer layer of cells up to several times that size. They are of oval shape, and take the stains to about the same degree as those of the inner set of cells; but there are usually some nuclei visible, which have the size, shape, and deep staining of the nuclei of the outer layer.

Various stages of division were clearly recognised in the large nuclei, which show a very distinct intranuclear network (Plate XXXVII. Fig. 7 and Plate XXXVIII. Figs. 8 to 10 ). So very different do the majority of the nuclei appear from the nuclei of the outer layer, where it is narrow or infiltrating old tissues, that it was difficult to believe they did not constitute a third class; but as the large plasmodia can be seen to be continuous with the outer layer, and as their protoplasm is similar, and as the transition forms, from the small deeply.stained 
up to the huge pale-stained nuclei, can be found in the plasmodia, it is clear that they belong to the same class as, and are derived from, the outer layer of the cell masses (Plate XXXVII. Figs. 8 and 10). The large plasmodia are only seen where the cell masses are large and growing freely among blood, though occasionally a large pink cell with large pale blue nucleus is found among the infiltrating processes, indicating that their elements are present in these processes. Their free edges have nothing like a cell wall, but lie naked to the blood.

The blood in which the young cell processes lie, though to appearance extravasated, seems to have been healthy uncoagulated blood, as in the circulation, because the corpuscles are well preserved, and when tested by Weigert's fibrin stain it shows no fibrin. The blood, on the other hand, lying among degenerated or necrosed cell masses, shows an abundant fibrin network; the more complete the necrosis the more abundant the fibrin. It is also noticed that the blood, whether among the cell masses or in vessels, contains an unusually large number of leucocytes. Numerous leucocytes are also to be seen among the cells of the degenerated cell masses; there is no such infiltration of the young growing ones.

The cell masses have neither fibrous stroma nor blood vessels of their own. In the zone of fine cell processes infiltrating old tissues there is always abundance of fibrous stroma, representing remains of the invaded normal tissues, and disappearing as the cell masses grow larger. This is well seen in the lung and where large blood vessels are being infiltrated (Plate XXXVII. Figs. 3 to 6 ).

Some of the degenerative changes which overtake the tumour cells have already been referred to. They alter the appearance of the cells to a very great degree, and in general they tend to obscure the differences between the different classes of them (Plate XXXIX. Figs. 13 and 14).

In the inner layer the protoplasm of the cells shrivels up and becomes granular, the swollen nuclei become more irregular in size and shape, and less distinct; finally, the nuclear staining is lost, and the mass becomes indistinguishable from old blood clot. In the plasmodia vacuolation also occurs, but irregularly throughout the protoplasm, not around the nuclei, as in the cell masses of the inner layer. The nuclei become swollen, distorted, and in the end likewise cease to stain. The degenerative changes are usually about equally advanced in both classes of cells, but the last remains which are distinguishable in the completely necrosed areas are large rounded homogeneous masses, staining deeply with eosin, which seem to be remains of the plasmodia.

A modification of the cells of a degenerative nature, which is often seen, especially in the large masses in invaded blood vessels, is an increase in the size of both cells and nuclei, with very little appear- 
ance of vacuolation, and the assumption of a spindle shape (Plate XXXIX. Fig. 14). The nuclei become large and granular and of irregular shapes; the protoplasm becomes coarsely granular, and tends to take a dark colour from the stains. The cells of both layers are represented, but it becomes difficult to tell which layer any given cells belonged to, except occasionally in the case of a mass of the homogeneous finely granular protoplasm, or small dark stained nucleus of a plasmodial process of the outer layer. The absence of vacuolation and the peculiar shape of the cells appear to be due to the degenerative changes occurring under pressure. The degeneration appearances are of great importance, as, in scrapings taken for examination during the life of the patient, it is degenerated cells which are most likely to be found. It certainly appears to have been so in the present case, as the cells of the tumour (in a portion removed with the curette on October 3) were at first reported to be decidual cells. This point will be referred to again, when the question of the nature of the tumour cells is considered.

On comparing the sections of the tumour with sections of young placentæ, there was no difficulty in recognising the elements to which the cells of the tumour correspond, namely, the epithelium of the chorionic villi (Plate XXXVIII. Figs. 11 and 12 ; Plate XXXIX. Figs. 16 and 17). As a rule, in young, well-preserved villi two layers of epithelium are distinguishable. As to the nature and origin of these, opinions are divided; some authorities holding them to be entirely fotal, others believing that the outer layer is a maternal tissue. Whatever be their nature, the following are the characters they present.

The outer layer consists of a thin stratum of finely granular protoplasm, showing no differentiation into distinct cells, and having scattered through it at irregular intervals small oval nuclei, which stain deeply with hæmalum or other nuclear stains; the protoplasm stains deeply with eosin. This layer frequently spreads out into large plasmodia, with protoplasm and nuclei similar to those of the narrow stratum. The free surface of this layer lies naked to the blood of the intervillous spaces. The inner layer, continuous with the outer, consists of cells, for the most part distinctly differentiated from one another, with clear, lightly-staining protoplasm, and large round or oval nuclei, which stain comparatively lightly with hæmalum, and show a distinct intranuclear network. A distinct basement membrane, separating them from the connective tissue stroma of the villus, is often recognisable (Plate XXXVIII. Figs. 11 and 12). This layer at most points where a villus is attached to the decidua, and also here and there throughout the placenta, spreads out into a large mass of cells (Plate XXXVIII. Figs. 11 and 12 ; Plate XXXIX. Figs. 16, and 17). There is often a certain amount of shrinkage of the protoplasm away from the nucleus. Comparison of those two layers 
of cells with the cell masses of the tumours shows the cells of the inner layer (Langhans') identical in all respects with those of the inner layer of the tumour masses, even to showing similar degeneration appearances. The narrow stratum of the outer layer (the syncytium) equally closely resembles the outer layer of the tumour masses, except in regard to the plasmodia. Whereas in the tumour the plasmodia show nuclei of very various sizes and degrees of staining, in the placenta they show nuclei all about the same size, small, oval in shape, and staining deeply.

No decidua cells were found in any of the numerous sections of tumour examined. The only cells at all resembling decidua cells were some of those in the degenerated masses, especially, of course, those which had assumed a spindle shape (Plate XXXIX. Fig. 14), but the resemblance is very slight. An illustration of normal decidua is given for contrast (Plate XXXIX. Fig. 15). The degenerated tumour cells have none of the regularity in size and arrangement of decidua cells; their nuclei are larger and their protoplasm far less homogeneous; even degenerated decidua cells could hardly be confounded with any of the tumour cells. Also, there is the absence of any fibrous stroma among the tumour cells. The elements corresponding to the tumour cells were studied principally in ordinary intrauterine placentæ of from eight weeks to four months, and also in two placente in the Fallopian tube, which had been removed by operation. These Fallopian placentæe show the elements corresponding to the two layers of tumour cells, quite as elearly as the intrauterine placentæ. In two of these no cells having the characters of decidual cells could be found; in other two there was abundance of decidual cells between the villi and the fibrous and muscular wall of the tube. In the specimen from which Plate XXXIX. Fig, 17 is taken the villi are attached directly to fibrous tissue of the mucous membrane of the Fallopian tube by a mass of cells of the deep layer of chorionic epithelium, which seem to infiltrate it to a very slight degree, and the superficial layer of cells forms a border to this mass and spreads out a little on either side over the surface of the Fallopian tube tissue. The inner layer of Fallopian tube tissue appears, to some extent, necrosed, resembling the layer of necrosed tissue which commonly separates the membrana decidua from the intervillous space and the tips of attached villi. The attachment of the young tumour cell masses to adjacent more or less necrosed old tissues often shows a striking resemblance to the attachment of the villi just described; it is shown in Plate XXXVII. Fig. 7.

A chorionic villus from a tubal placenta forms the subject of Plate XXXIX. Fig. 17 ; a normal villus from a fourth-month intrauterine placenta the subject of Fig. 16 on same Plate. The latter is attached by a wide layer of cells of the deep layer of epithelium (Langhans' layer) to a piece of living decidua; some of these cells can be traced in among the decidual cells. Many of them have assumed 
a spindle shape, but there is no possibility of confounding them with the decidual cells. Both figures show an abundance of plasmodia with the small dark stained nuclei, and granular undifferentiated protoplasm characteristic of the syncytium.

The tumour tissue, then, appears to be entirely derived from the two layers of the epithelium of the chorionic villi. As it has been mentioned that there is absolutely no fibrous stroma belonging to the tumour, it is almost superfluous to say that no such thing as a chorionic villus was observed in it; the new growth is purely epithelial. As to the differences between the plasmodia in the tumour and in the placenta little explanation can be offered. 'To judge by the frequency with which nuclear division is to be seen, they are certainly to be regarded as signs of the abnormal activity of the tissue. Nothing exactly like the plasmodia of the tumour was seen in any of the placentix examined. One of these, it may be mentioned, was the subject of hydatidiform degeneration in a very early staye.

The large plasmodium in Plate XXXVIII. Fig. 8 shows, at the point corresponding to the letter $D$ in the line diagram, a large body of sharply circular outline with a well-defined nucleus, about the size of one of the nuclei of the inner layer of cells placed concentrically in it. The protoplasm of this body in the original specimen is stained lightly with eosin, contrasting strongly with the deeply stained protoplasm of the plasmodium. Its nucleus is light blue with the hæmalum. Several objects like this were seen, all of them in young well-preserved plasmodia. They present a very close resemblance to some of the objects figured by Ruffer and Walker, ${ }^{1}$ as parasitic protozoa in cancerous tumours, but I am strongly inclined to regard them as only sections of cells of the inner layer which have become invaginated into the plasmodia. They measure about one-thousandth of an inch in diameter, the nucleus about half that,-rather above the average size of the tumour cells of the inner layer.

There remain for consideration the relations of the tumour to the blood vessels and lymphatics, and the distribution of the secondary growths. Infiltration of the tissues surrounding the growth has been already referred to. The earliest stage, at the very edge of the growth, shows the old tissues permeated by tumour cell processes; the later stages show a gradual lessening of the old tissue as the tumour tissues increase, and necrotic changes overtaking the remains; finally, there is little or no trace of old tissues left. There is, in fact, a complete destruction of the old tissues. As the tumour carries no fibrous stroma of its own, it is plain that an infiltrated vessel wall must be weakened and destroyed by this process; and as the blood appears not to coagulate around the young processes, hæmorrhage is bound to occur. This explains the large amount of blood in the tumours and the hæmorrhages which are so terrible a feature of the disease clinically.

1 Journ. Path. and Bacteriol., Edin. and London, 1893, vol. i. p. 198. 
The illustration of the wall of the internal iliac vein (Plate XXXVII. Fig. 5-perhaps best of the illustrations) shows this destruetion of the old tissues.

Even apart from microscopic appearances, the destruction of the walls of the blood vessels was clearly recognised with the naked eye, in the dissection of the secondary tumours at the sides of the cervix uteri.

The vessels which are chiefly invaded are the veins and capillaries. The illustrations of the uterine wall (Plate XXXVII. Figs. 3 and 4) show tumour masses growing in the uterine veins. The thick middle coat of the arteries seems to resist the tumour very strongly, as in the sections it was the rule to find it intact even where the outer coat was infiltrated to a considerable degree. Occasionally growths were seen inside small arteries.

Once inside the vessels the tumour seems to grow along their walls to a considerable extent without invading them. This would account for the size to which the vessels get distended by the neoplasms inside them. The enormous distension of the vaginal veins is more by blood clot than by tumour; the tumour tissue is chiefly along the side of these vessels. One or two tumours in blood vessels and that in the Fallopian tube showed no living tumour tissue at all, as if, after growing for a time and distending the vessel (or tube) they had been cut off from all nourishment of the blood, and had undergone complete necrosis. The areas of necrosed tumour tissue and blood clot usually show a great deal of dissolved-out blood pigment, which tends to gather into dark streaks. The remains of tumour cells in the completely necrosed nodules just mentioned are full of this brown pigment.

The relation of the tumour to the lymphatics was not so satisfactorily made out in the seetions. The cell processes are seen in the interstices of the tissues, which are drained by the lymphatics; also, masses of cells are seen growing by the sides of blood vessels in spaces with thin fibrous walls, which strongly suggest the perivascular lymph spaces.

Apart from this, however, the facts-(1) that remains of lymphatic gland tissue were found in the tumours about the branches of the internal iliac veins; (2) that the uterine branches of these veins, even though occupied by tumour where they emerge from the uterus, run for some distance quite normal, and then again become the seat of tumours; and (3) that the vesical and vaginal veins emerge from tumour-free viscera, to become invaded before they join the uterine vessels, prove that extension takes place by the lymphatics. The metastases in the lungs are of course due to extensions by the blood stream, which might be either from the primary tumour directly, or from the secondary invasions of the branches of the internal iliac veins, by the tumour in the glands about the base of the broad liga- 
ments on those trunks. The absence of involvement of the rectum and its vessels saves the liver from secondary growths. The suspected areas in the spleen were not tumour nodules; nothing of the nature of tumour was found in any of the other abdominal or thoracic viscera, or in the limbs.

From the absence of secondary growths beyond the lungs it is clear that the emboli which carry the infection by the blood stream must be of such size as to be arrested in the capillaries of the lungs. Why the branches of the pulmonary vein had not been infected like the systemic veins, and so carried the growth to all parts of the body is a mystery; and it is much to be regretted that the bronchial lymphatic glands were not examined and retained for microscopic investigation.

Round the tumour nodules in the lungs there is seen to be a certain amount of consolidation, partly due to pressure, but partly inflammatory, as is indicated by the presence of masses of fibrin, like those which are formed in the alveoli in pneumonia. Considerable round-cell infiltration is also to be seen round the tumours in the lymphatic glands.

In conclusion, then, it appears that this tumour, like a number of others which have been described by German and American authors, has originated from the epithelium covering the chorionic villi. Further, it is the opinion of the authors of this report that it has been clearly made out that both layers of the epithelium of the villi are represented in the tumour. On account of alterations due to pressure in infiltrating the normal tissues, and the changes of a degenerative and necrotic nature which overtake the cell processes, this point cannot be made out in many parts of the growth; but in several parts, which had the characters of actively growing and well preserved tissues, they believe that they have clearly recognised the two kinds of cells, growing in the same close and intimate relationship to one another as in the normal placenta; thus supporting the opinions so ably expressed by Marchand.

In view of its epithelial origin, and the manner in which it infiltrates the adjacent structures, and the secondary involvement of the lymphatic glands connected with the primary tumour, the growth appears to have much more affinity with carcinoma than with sarcoma, though the manner in which it spreads by the blood stream directly and at an early period is more characteristic of the latter class of growths. In view, however, of the peculiar circumstances of its period of occurrence, and the peculiar structures from which it originates, they are inclined to agree with Marchand, that it should rather be regarded as a tumour suigeneris. On this point judgment may be suspended till more is known about such tumours, and about the chorionic epithelium. 


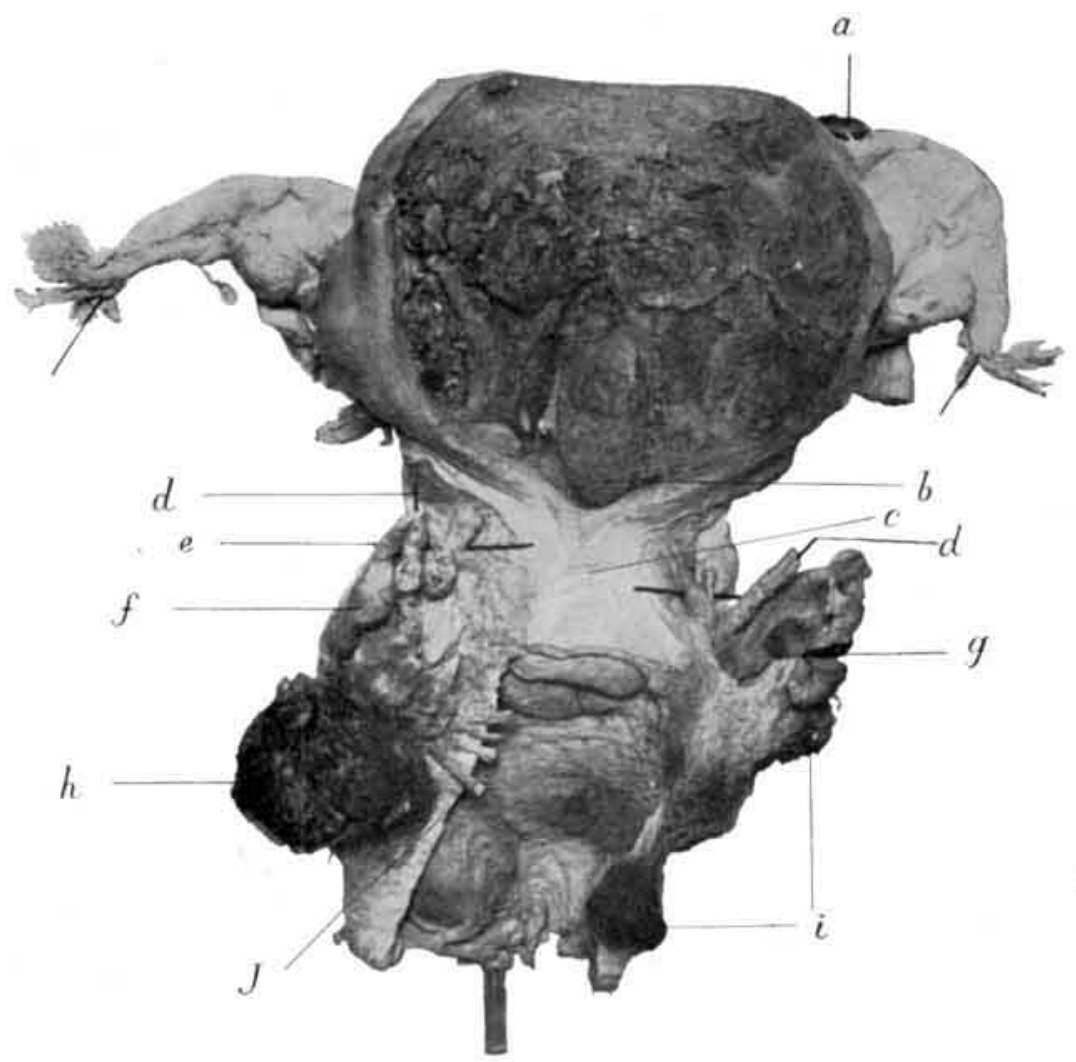

Fig. 1.

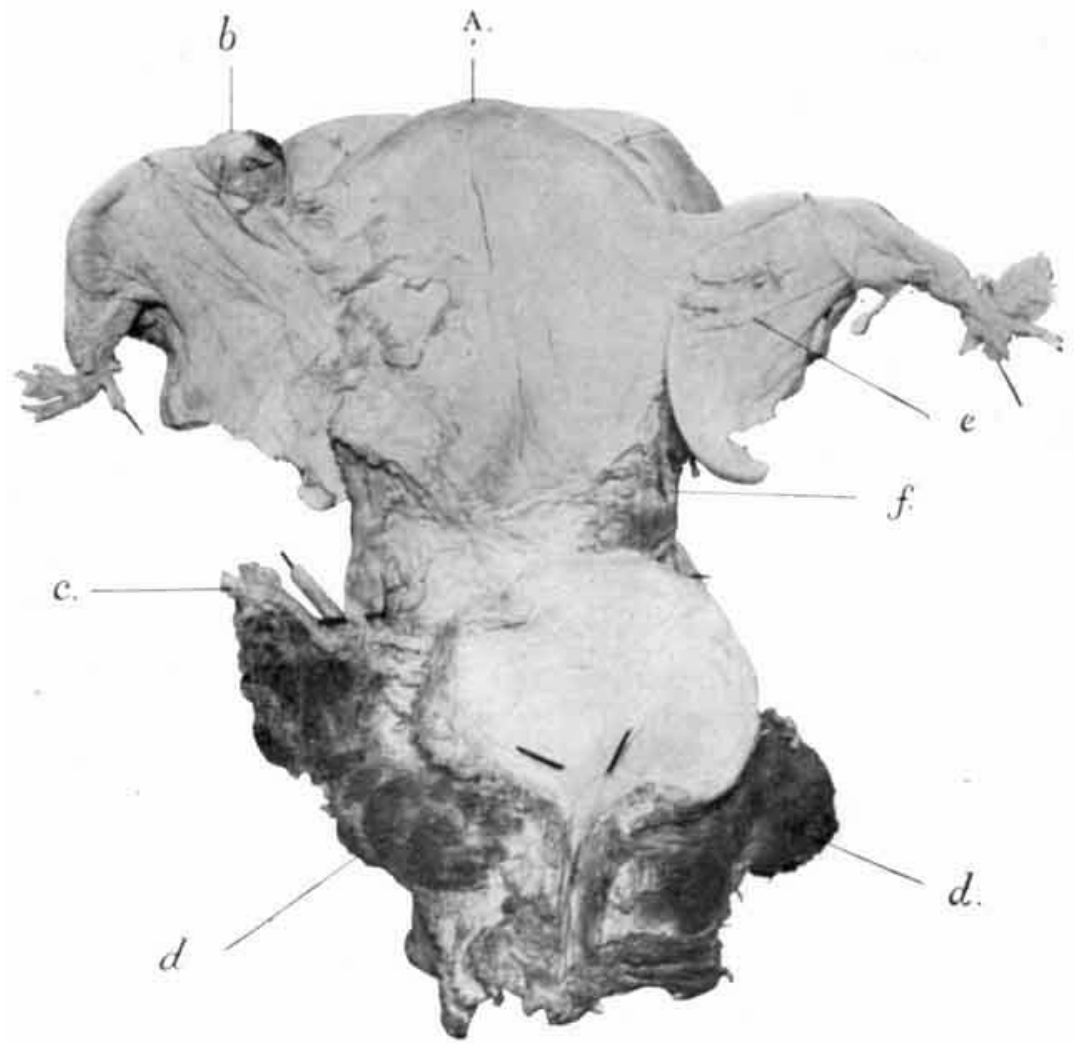

Fic. 2. 


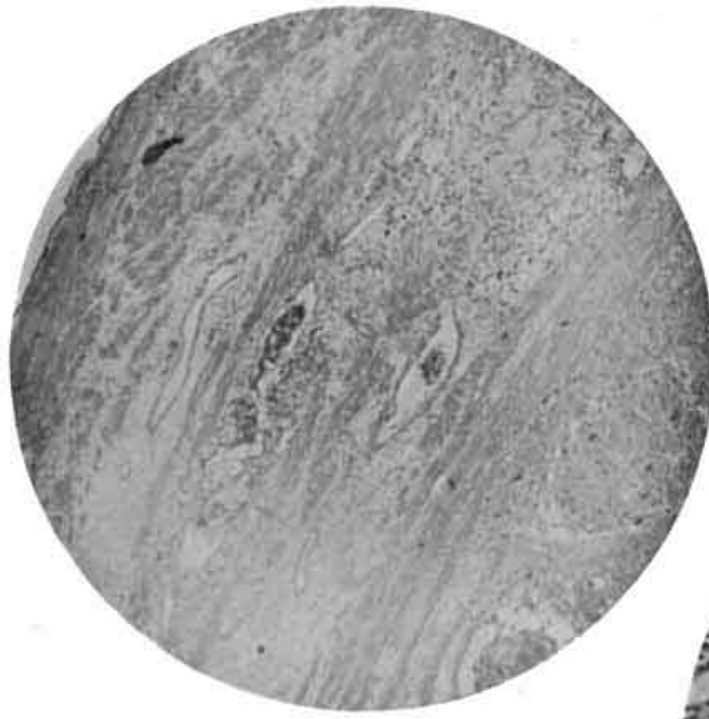

Fig. 3.

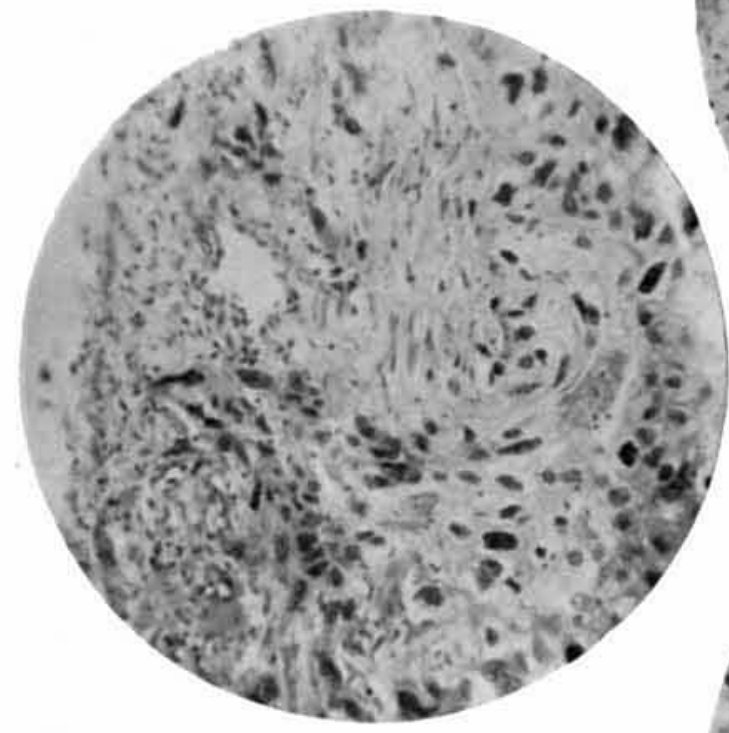

Fig. 5 .

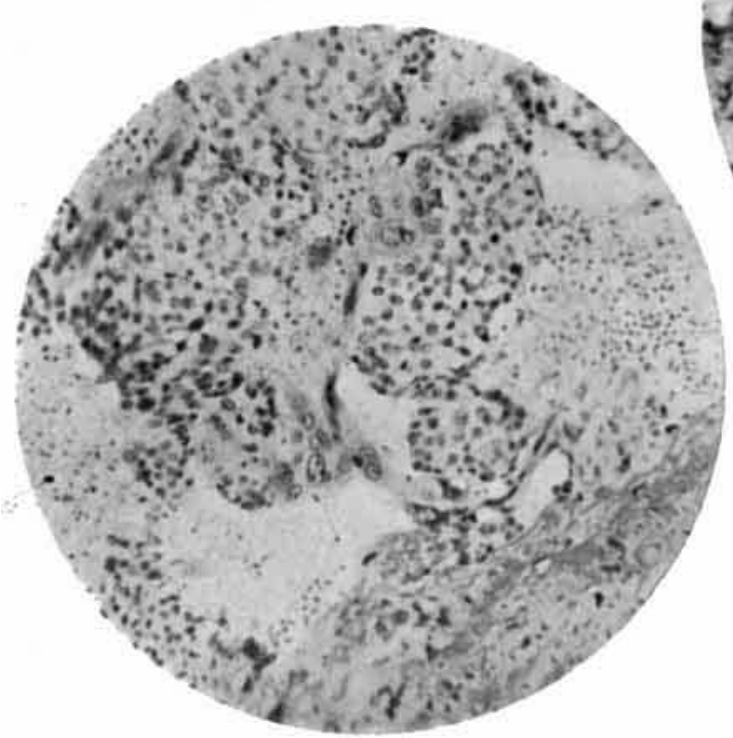

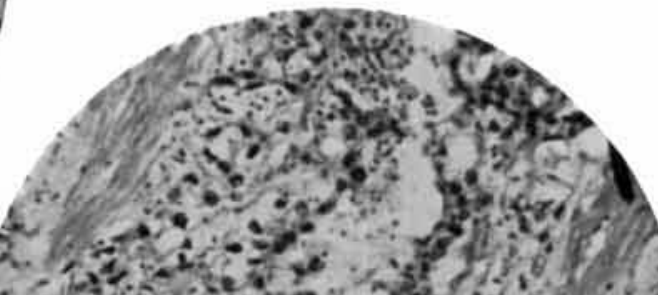

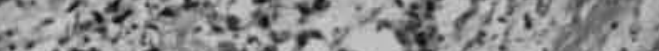

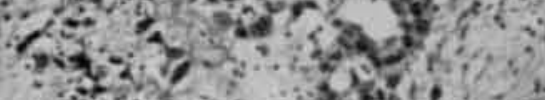

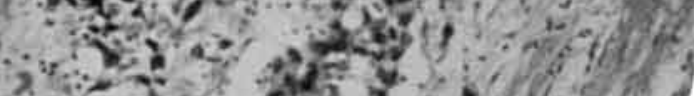

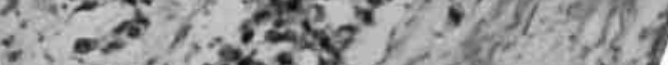

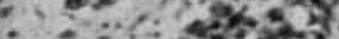

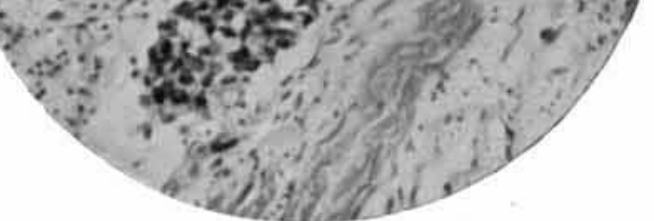

Fig. 4 .

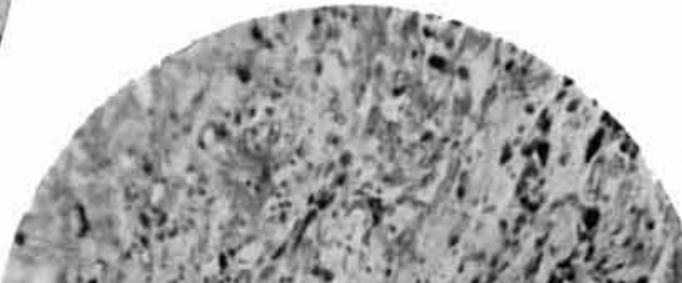

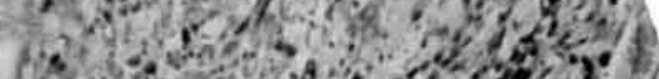
2.

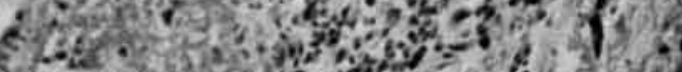

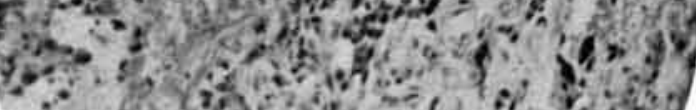

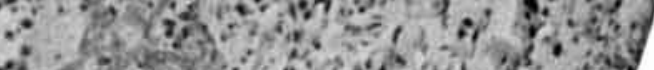

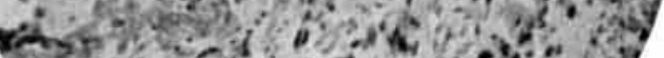

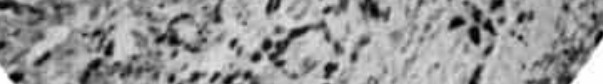
Fie. 7 , Fie. 6. 


\section{BIBLIOGRAPHY.}

The fullest list in English of the literature of the subject appears in the last edition of Hart and Barbour's " Manual of Gynæcology" (Edinburgh and London, 1897), along with an excellent summary of the principal facts about such cases as are at present known.

1. Marchand . . . . . Monatschr. f. Geburtsh. u. Gynaek., Berlin, 1895, Bd. i. S. $419,513$.

2. Whittridge, William . . Johns Hopkins Hosp. Rep., Baltimore, 1895, No. 9. vol. iv. Also gives the literature very fully.

\section{DESCRIPTION OF PLATES XXXVI.-XXXIX.}

\section{Plate XXXVi.}

FIG. 1.-Posterior view of pelvic organs, dissected; the rectum and posterior wall of the vagina removed. The primary tumour, occupying nearly the whole of the posterior surface of the body of the uterus, has been split in the middle line (not quite through), and the two halves turned aside to show its appearance in section. The Fallopian tubes are marked by bristles. The secondary tumours in the lymphatic glands on the internal iliac vessels and in the adjacent veins, form considerable masses to right and left of the cervix uteri. A little less than half natural size.

a. Tumour nodule in right Fallopian tube.

$b$. Lower end of uterine tumour, projecting into cervix uteri.

c. Posterior surface of cervix uteri, uncut; the lips of the os uteri are considerably thickened.

$d$. The ureters marked by bristles.

$e$. Uterine vessels on the left side, a bristle passed under them.

$f$. On the left, a large vein from bladder, distended by tumour.

$g$. On the right, large vein (trunk of internal iliac), distended with tumour, a wedge removed for microscopic examination (vide Fig. 5).

$h$. Tumour in vaginal vessels, on left, incised at autopsy, showing appearance of the tumour tissue.

$i$. Vaginal tumours in section.

$j$. Uninvolved veins, which rose from the back of the vagina, passing into the tumour mass and becoming distended with it.

Fig. 2,-Anterior view of the pelvic organs, dissected ; the anterior parts of the bladder removed and the urethra slit open in front; the ureters marked by bristles. The bladder was displaced slightly towards the left.

a. Is placed opposite the top of the fundus uteri. To right and left is seen the top of the tumour, slightly lobulated.

b. Tumour in the Fallopian tube.

c. Uterine artery on the right, lying in a groove on the top of the secondary tumour. The inner end of the horizontal bristle points to the continuation of the artery on the side of the cervix uteri.

d. Tunour in the vaginal veins.

e. Ovarian vessels on the left side.

$f$. Anastomosing vessel between the uterine and the ovarian vessels.

\section{Plate XXXVII.}

Frg. 3.-Section of uterine wall invaded by tumour, showing infiltration of the connective tissue planes among the muscular bundles, and tumour cells in the uterine veins. $(x$ 24. $)$ 
Fig. 4. - Portion of the same, more highly magnified, showing the invaded veins. $(\times 260$.

Fra. 5. - Portion of wall of internal iliac vein, showing tumour cells infiltrating it from the inside; one process of tumour cells has almost penetrated it after destroying the muscular coat. ( $\times 260$.)

Fig. 6.-Tumour processes infiltrating compressed lung. $(\times 130$.

Fra. 7.-Young tumour tissue growing in uncoagulated blood; from a large secondary nodule in the lung. At one side is seen the attachment of the tumour cell mass to partially necrosed lung tissue. Cf. Figs. 9 and 10. ( $\times 130$.

\section{Plate XXXVIII.}

FIG. 8. - Young tumour cell masses, from the same part as the preceding, more highly magnified; the different elements are indicated by letters on the corresponding parts of the line diagram (Fig. 9). ( $\times 260$.

FIG. 9. -Line diagram traced over a print of the preceding figure.

aaa. Plasmodia of the outer layer of the cell masses, corresponding to the outer layer of the epithelium of the chorionic villus (syncytium).

$b b b$. Cell masses, inner layer, corresponding to the inner layer of the epithelium of the chorionic villus (Langhans' layer).

ccc. Blood, showing numerous leucocytes, between the cell masses; for clearness the blood is not drawn in the diagram.

d. Cell of inner layer invaginated into plasmodium.

The outlines of the cells of the inner layer are indicated clearly in the diagram; they could be seen much more distinctly under the microscope (by alterations of focus) than appears in the photograph from which the figure was prepared.

FIG. 10. -Tumour cell mass, showing the inner and outer layers with particular distinetness. At four points the outer layer spreads ont into plasmodia, one of which shows large vacuoles. $a$ is placed in the cell mass (on a black spot due to a mass of adventitious matter in the preparation). ( $\times 260$.

Fra. 11.-Chorionic villi from an apparently healthy placenta, in an abortion in the eighth week. For the most part there was no blood in the intervillous spaces. Cf. Fig. 13. ( $\times 130$.

FIG. 12.-A portion of the same as the preceding figure, more highly magnified, showing the epithelium of the chorionic villi. Between the villi are seen several multinucleated plasmodia belonging to the outer layer of the epithelium (syncytium) two of them evidently prolongations of it, the third appearing as if detached. Two cell masses formed by proliferation of the inner (Langhans'), layer are seen. $(\times 260$.

\section{Plate XXXIX.}

Frg. 13.-Degenerated tumour cells, from cell masses which had been growing, like the subjects of Figs. 8 to 11, freely in uncoagulated blood $(\times 260$.

Fig. 14.-Degenerated tumour cells, from a mass of tumour growing in a small, thickwalled vessel, apparently under pressure, showing the short spindled shape frequently assumed by degenerating cells, and which might lead to their being taken for decidua cells. $(\times 260$.

Fig. 15. - Portion of normal decidua for contrast with the preceding, from the decidua serotina of an abortion in the fourth month. The void space is the Iumen of a uterine gland; its epithelium is only fairly well preserved. $(\times 260$. 

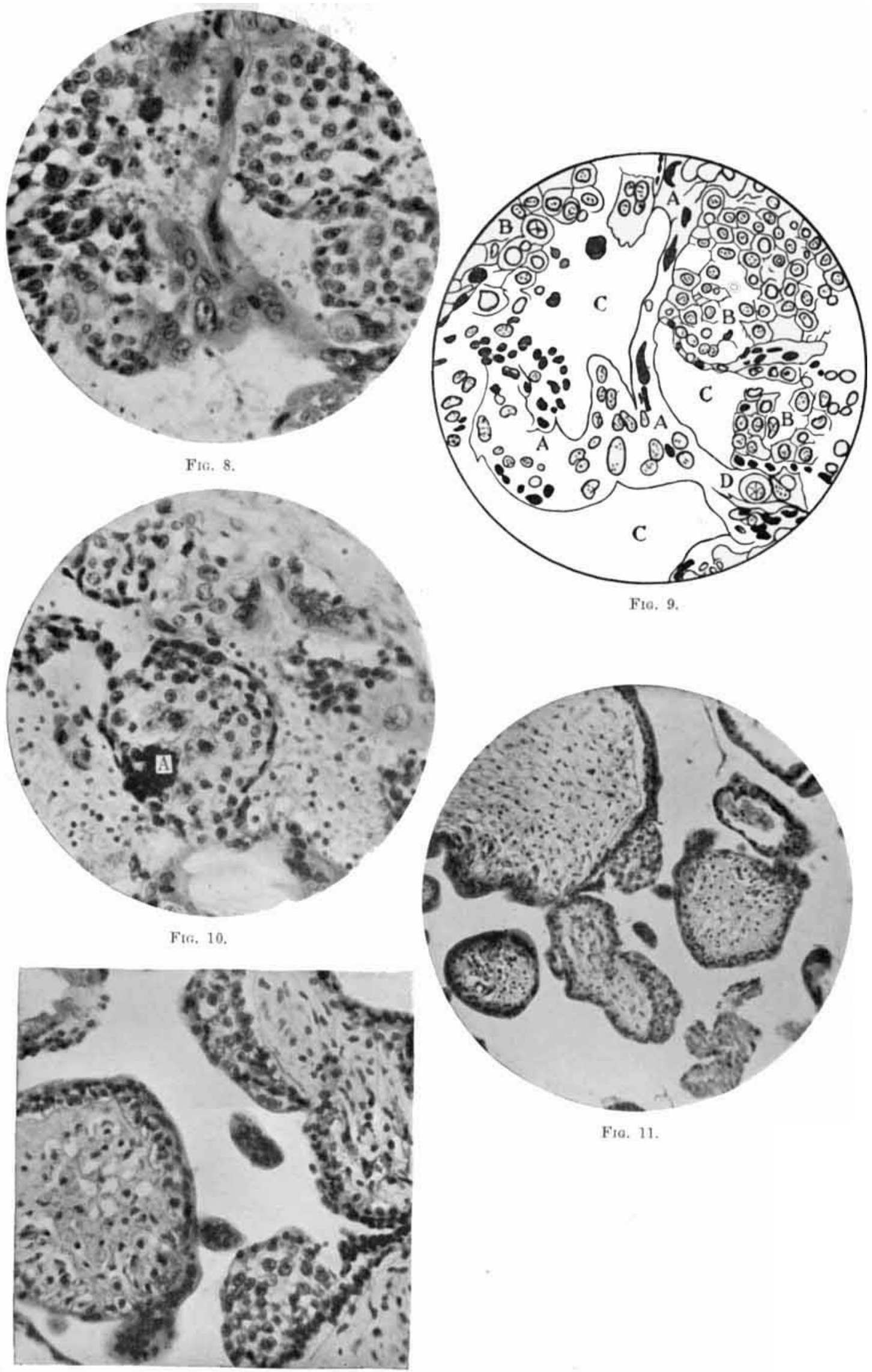

Fı, 9.

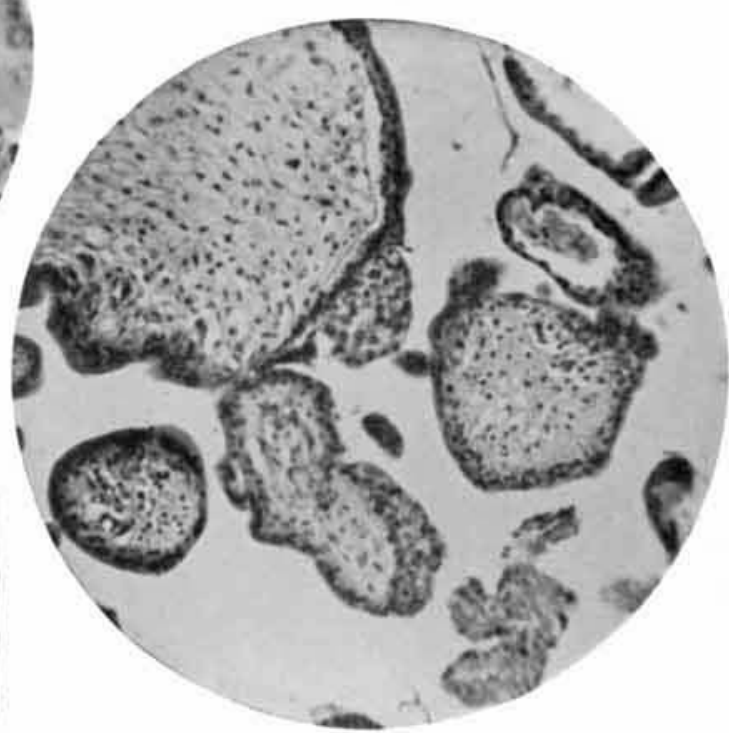

Fro. 11. 


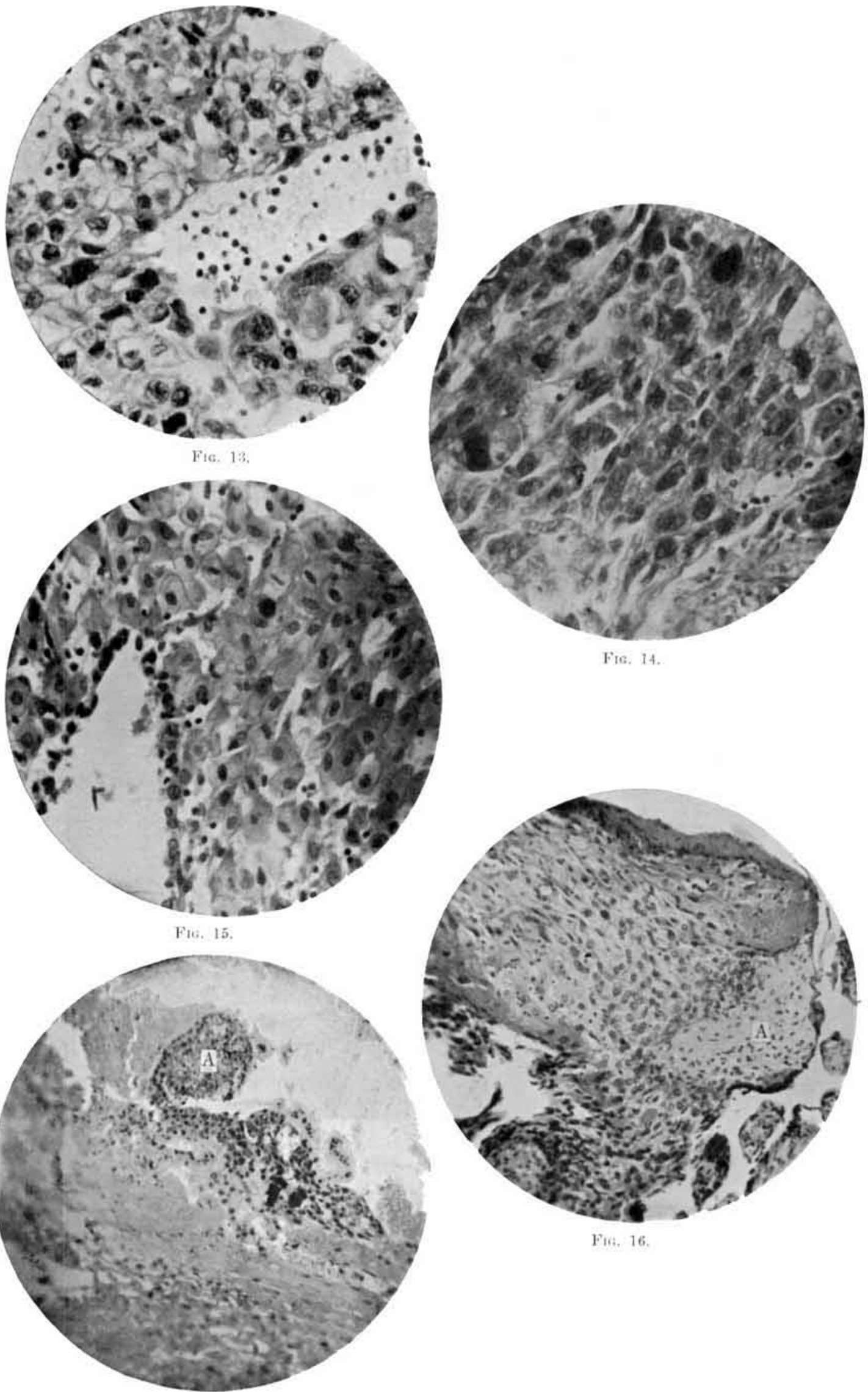

Fro. 17. 
Fig. 16.-Villus attached to decidua from a placenta of an abortion in the fourth month.

$a$ is placed in the centre of the villus, which has a very dense fibrous appearance.

The cells of Langhans' layer form a broad zone and pass in among the decidua cells to a slight extent. At one side is seen a layer of necrosed tissue, separating the living decidua from the intervillous space. Several multinucleated plasmodia of the syncytium are also visible. $(\times 130$.

Fig. 17.-Villus from a tubal pregnancy, supposed five or six weeks, showing its attachment to the fibrous tissue of the Fallopian tube, which appears partially necrosed. There is nothing like decidua visible. There are a number of plasmodia of the syncytium and a considerable expansion of Langhans' layer. The villus is partly torn between its fibrous core and the epithelium at the side next the tube wall. $\alpha$ is in the centre of the villus. ( $\times 130$. 